\title{
A CONTRIBUIÇÃO DAS UNIVERSIDADES COMUNITÁRIAS NOS PROCESSOS DE REGULARIZAÇÃO FUNDIÁRIA URBANA: A EXPERIÊNCIA DA UNIJUÍ VIA PROJETO DE EXTENSÃO
}

\section{THE CONTRIBUTION OF COMMUNITY UNIVERSITIES IN URBAN ENVIRONMENTAL REGULARIZATION PROCESSES: THE EXPERIENCE OF UNIJUÍ BY THE UNIVERSITY EXTENSION}

\section{RESUMO}

O Projeto de Extensão Universitária "Regularização fundiária urbana: direito social à moradia digna", vinculado ao Departamento de Ciências Jurídicas e Sociais da Universidade Regional do Noroeste do Estado do RS - UNIJUÍ, tem o objetivo de promover, em parceria com o poder público municipal, a regularização fundiária urbana nos municípios de Ijuí, Santa Rosa e Três Passos, garantindo aos moradores/ocupantes de imóveis em situação de clandestinidade/irregularidade, pertencentes a segmentos sociais vulneráveis e hipossuficientes economicamente, além do direito social à moradia, a efetivação de seu direito à propriedade, nos termos da Lei n. ${ }^{\circ}$ 13.465/2017.

PALAVRAS-CHAVE: Direito Social à Moradia, Ocupação Desordenada do Solo Urbano, Núcleos Urbanos Informais, Regularização Fundiária, Extensão Universitária.

\begin{abstract}
The University Extension Project "Urban land regularization: social right to decent housing", linked to the Department of Juridical and Social Sciences of the Regional University of the Northwest of the State of RS - UNIJUÍ, aims to promote, in partnership with the municipal public power, the urban land regularization in the municipalities of Ijuí, Santa Rosa and Três Passos, guaranteeing the residents/occupants of properties in a situation of clandestinity/ irregularity, belonging to vulnerable and economically vulnerable social segments, in addition to the social right to housing, right to property, pursuant to Law $n^{\circ}$. 13.465/2017.
\end{abstract}

KEY-WORDS: Social Right to Housing, Disorganized Occupation of Urban Land, Informal Urban Centers, Land Regularization, University Extension.

\footnotetext{
${ }^{1}$ Bacharel em Ciências Jurídicas e Sociais (UFSM). Especialista em Direito Público (UNIJUÍ). Mestre em Direito (UNISINOS). Professora do Curso de Graduação em Direito da UNIJUÍ. E-mail: pmoura@ unijui.edu.br.

${ }^{2}$ Bacharel em Ciências Jurídicas e Sociais (UNIJUÍ-RS); Especialista em Direito Público (UNIJUÍ); Mestrado em Direito (UNISC-RS). Professora do Curso de Graduação em Direito (UNIJUÍ). Advogada. E-mail: poliveski@unijui.edu.br
} 


\section{Introdução}

A ocupação desordenada do território dos Municípios de Ijuí, Santa Rosa e Três Passos, situados no noroeste do Estado do RS, decorre, essencialmente, da proliferação de parcelamentos irregulares ou clandestinos do solo urbano, comumente denominados de “ocupações”. Referidas ocupações causam prejuízos a todos os cidadãos, na medida em que os privam dos direitos coletivos e difusos ao meio ambiente ecologicamente equilibrado, à cidade sustentável e democrática e à sadia qualidade de vida. Isso porque a ocupação desordenada gera um grave problema ambiental, causado pela falta de proteção de vegetação em áreas de preservação permanente, emissão de esgoto sem tratamento nos rios e córregos que cortam os lotes, inexistência de saneamento básico e infraestrutura adequada, causando danos econômicos, sociais e ambientais.

Diante dessa realidade, surge a necessidade de construção de um verdadeiro pacto social entre os diversos atores envolvidos, com a finalidade de regularizar a ocupação e os parcelamentos de solo, tidos como potencialmente degradantes do meio ambiente, sobretudo quando implantados de forma irregular, à margem dos licenciamentos urbanísticos e ambientais e das obras de saneamento legalmente exigidas para evitar, mitigar e compensar os danos ambientais, urbanísticos e sociais decorrentes deste parcelamento do solo, culminando na promoção do processo de titulação dos lotes aos moradores.

Tais medidas passaram a ser juridicamente viáveis com o implemento da Lei Federal $\mathrm{n}^{\mathrm{o}}$ 13.465/2017, mediante a elaboração de um Projeto de Regularização Fundiária Urbana (Reurb), que passa a ser o instrumento jurídico de política urbana do território nacional, que visa à regularização de núcleos urbanos informais e da situação jurídica de seus ocupantes. Denota-se, assim, a preocupação legal de que o uso, o parcelamento e a ocupação do solo urbano ocorram de forma ordenada, garantindo aos cidadãos condições mínimas de habitabilidade e assegurando, assim, o direito à moradia digna e à cidade.

Nesse contexto, e pensando na cooperação entre entes públicos governamentais, iniciativa privada e demais setores da sociedade civil, a fim de propor e executar ações que visem à regularização fundiária urbana, inserem-se os projetos de extensão universitária, já que as Universidades Comunitárias se enquadram entre os entes públicos não-estatais, que podem 
contribuir para o desenvolvimento social de suas regiões de abrangência, como é o caso da UNIJUÍ - Universidade Regional do Noroeste do Estado do Rio Grande do Sul.

A extensão universitária é um espaço fértil para a problematização e identificação de objetos de pesquisa acadêmica, desafiando o corpo docente a programar ações pedagógicas que despertem nos graduandos o interesse pelo conhecimento, investigação da realidade social, identificação de problemas sociais e busca por soluções. Isto permite a reflexão coletiva e crítica sobre as diferentes temáticas trabalhadas, de modo que alunos(as) e professores(as) sejam instigados(as) a promover pesquisa científica capaz de compreender a realidade e propor novas ações e políticas públicas que visem à melhoria das condições de vida, ao desenvolvimento e à construção da cidadania.

Neste aspecto, no ano de 2018, foi proposto e aprovado um projeto de extensão universitária, a ser executado por professores e alunos bolsistas vinculados ao Curso de Graduação em Direito da Unijuí, com a colaboração do corpo docente e discente também dos Cursos de Arquitetura, de Engenharia Civil e de Comunicação Social, denominado "Regularização Fundiária Urbana (REURB): direito social à moradia digna", a ser executado, inicialmente, durante os anos de 2019 e 2020.

Por meio das ações propostas pelo projeto, entende-se que a população dos municípios envolvidos seria beneficiada pela Reurb, tendo em vista que a implementação do Projeto de Regularização Fundiária Urbana exige a adequação dos núcleos urbanos informais às normas urbanísticas e ambientais. Nesse viés, a capacitação e o envolvimento dos acadêmicos dos cursos integrantes do projeto com a temática central poderá desenvolver, ainda, as competências e habilidades necessárias ao exercício profissional, comprometido com o desenvolvimento regional e com as problemáticas sociais, atendendo às expectativas da política e das diretrizes de extensão da Unijuí.

\section{O contexto em que se insere a legitimação fundiária urbana e o papel do poder público}

O planejamento e a administração eficiente e eficaz de transformação dos espaços urbanos nos municípios se tornam de fundamental importância no atual contexto socioespacial mundial, nacional, regional e local. A construção e o desenvolvimento de cidades, cada vez mais sustentáveis, constituem uma premissa imprescindível para a qualidade de vida desta e das próximas gerações. A visão social mostra-se importante para um novo olhar do desenvolvimento urbano contemporâneo. Trata-se da sustentabilidade da própria existência humana. 
Nesse viés, a Organização das Nações Unidas (ONU), da qual o Brasil é integrante, estabeleceu convenção no sentido de que a moradia constitui-se em direito social fundamental do cidadão, razão pela qual a Emenda Constitucional n 26/2000 incluiu entre os preceitos da Constituição Brasileira de 1988 a moradia como direito social fundamental. No mesmo sentido, o texto constitucional brasileiro (art. 225, caput) também garante a todos direito ao meio ambiente ecologicamente equilibrado, bem jurídico essencial à sadia qualidade de vida, impondo à coletividade e ao poder público o dever de defendê-lo e preservá-lo para as presentes e futuras gerações. (BRASIL, 1988).

Na medida em que a Declaração Universal dos Direitos Humanos, de dezembro de 1948, prevê em seu art. 25 que "Toda pessoa tem direito a um padrão de vida capaz de assegurar a si e a sua família saúde e bem e bem-estar, inclusive alimentação, vestuário, habitação, cuidados médicos e os serviços sociais indispensáveis(...)”, e que o Brasil é signatário desse tratado internacional, e reconhece o direito à moradia como um direito social, não há como dissociá-lo de um importante princípio, fundante do Estado Democrático de Direito, que é o princípio da dignidade da pessoa humana.

Diz-se isso porque uma vida digna pressupõe o direito a um lar, um local a que todo e qualquer indivíduo tem direito, para que possa desfrutar de momentos de lazer e de privacidade com sua família, de repouso após dia exaustivo de trabalho, de não se sentir vulnerável sob o aspecto da vida com segurança, de não ter de viver na rua, dentre tantas outras necessidades que poderiam aqui ser citadas e que se relacionam com o direito à moradia com dignidade.

Falar sobre essa temática no contexto da sociedade brasileira na contemporaneidade perpassa a noção da importância que têm a implantação e implementação de políticas públicas de desenvolvimento social, que possam prever e executar metas e ações para o enfrentamento e a redução das mazelas voltadas para a falta de moradia digna no país, em especial em se tratando de pessoas que integrem segmentos sociais de vulnerabilidade e hipossuficiência social e financeira.

Claro que a problemática da falta de moradia digna no Brasil vai muito além da questão de ter ou não um título de propriedade. Há de se considerar que existe um número considerável de pessoas que vivem em áreas de ocupação irregular de solo urbano, muitas das quais vivendo em condomínios habitacionais ou loteamentos em situação de irregularidade, seja porque houve aquisição apenas da posse de áreas pertencentes a particulares, ou mesmo ao poder público, ou fruto, inclusive, de ocupação clandestina. Áreas em que foram edificadas moradias, que já se 
encontram, portanto, consolidadas, e cuja desocupação forçada não seria de fato a melhor saída, pois que os prejuízos seriam tão notórios que dispensam maiores comentários.

Além do que, moradias em situações irregulares, seja em razão de ocupações clandestinas ou não, em regra se consolidam em regiões urbanas que, ou não possuem infraestrutura básica de saneamento, de rede de esgoto, de fornecimento de energia elétrica, ou possuem em condições de precariedade. Sem mencionar que a falta de planejamento para a ocupação do solo urbano também põe em risco o direito ao meio ambiente sadio e equilibrado, na medida em que afeta, não raras as vezes, áreas de preservação ambiental, por exemplo.

Em contrapartida, há de se considerar que essa ocupação desordenada dos solos urbanos não pode ser atribuída, exclusivamente, a determinados segmentos da sociedade civil, em geral, os menos favorecidos social, cultural e economicamente. Trata-se de um fenômeno que vem crescendo e para o qual o poder público tem grande parcela de responsabilidade.

Assim, o crescimento das cidades tem provocado a fragmentação do espaço público e a exclusão social e territorial, sendo notório que a maioria das cidades brasileiras abriga algum tipo de ocupação irregular ou clandestina, de regra desprovida de infraestrutura mínima. O planejamento e a gestão eficiente, eficaz e efetiva de transformação dos espaços urbanos nos municípios se tornam de fundamental importância no atual contexto social e espacial, haja visto o incremento acelerado das populações urbanas.

Claramente, pode-se observar que a construção do espaço urbano tem sido marcada por inúmeros problemas, dentre os quais se pode citar a segregação espacial, a concentração de pobreza, a rarefação de facilidades, a violência urbana e a degradação do ambiente natural. Essa problemática, como menciona Henri Lefebvre (2001, p. 8081), "não é recente", mas demonstra que o poder público, embora tenha o dever legal de atuar para minimizar as mazelas sociais e atender ao interesse público, muito pouco tem feito no sentido de solucionar o problema. Basta verificar que Lefebvre (2001) mencionou o direito à cidade em 1968 (BIANCA TAVOLARI; JOICE BERTH, 2018) e, no Brasil, o direito à cidade como direito social fundamental do cidadão passou a integrar o ordenamento jurídico somente em 2000, com a Emenda Constitucional $n^{\circ} 26 / 2000$ e regulamentado com a Lei $n^{\circ} 13.465 / 2017$, a qual, em tese, possibilita legalmente o desenvolvimento de projetos de regularização fundiária.

Apesar disso, é importante referir que a Reurb não foi inventada agora. A legislação brasileira há muito tem se ocupado com esta questão. Desde a década de 1960, já se tinha o Movimento Nacional pela Reforma Urbana, um dos responsáveis pelo acolhimento, na 
Constituição de 1988, de um capítulo dedicado à política urbana (NELSON SAULE JR.; KARINA UZZO, 2015).

Ao longo das últimas décadas foram editados, no Brasil, alguns estatutos legais, a fim de regular o uso da propriedade urbana, pelo que se destacam alguns destes marcos jurídicos sobre o tema. Mas, é inegável que a Constituição Brasileira de 1988, em seus arts. 182 e 183, privilegiou a função social da propriedade e previu figuras como o plano diretor municipal, o parcelamento e a edificação compulsórios, o IPTU progressivo no tempo, a desapropriação com pagamento em títulos da dívida pública, redução de tempo para a usucapião de área urbana de até $250 \mathrm{~m}^{2}$, e a impossibilidade de usucapir imóveis públicos.

Visando a regulamentar os artigos 182 e 183 e a estabelecer diretrizes gerais da política urbana brasileira surge o Projeto de Lei do Senado n. ${ }^{\circ}$ 181/89, depois transformado no Projeto de Lei n. ${ }^{\circ}$ 5.788/90. Mais de uma década se passou até a sua aprovação, fazendo nascer, em 2001, o Estatuto da Cidade (Lei n. ${ }^{\circ}$ 10.257/2001), que deu destaque à regularização fundiária. Nessa legislação, ela aparece como diretriz geral (art. $2^{\circ}$, XIV) e instrumento jurídico de política urbana, não só de forma autônoma (art. 4º, V, "q"), mas também como um dos fundamentos para o direito de preempção (art. 26, I) e a transferência do direito de construir (art. 35, III), surgindo, ainda, como parte integrante das operações urbanas consorciadas (art. 32, §2 $2^{\circ}$ II).

O Estatuto da Cidade (Lei n. $\left.{ }^{\circ} 10.257 / 2001\right)$ é, portanto, uma legislação que fixa normas de ordem pública e interesse social reguladoras do uso da propriedade urbana em prol do bem coletivo, da segurança e do bem-estar dos cidadãos, bem como do equilíbrio ambiental. Suas normas são regulamentadas nos municípios em um Plano Diretor, que deve ordenar a ocupação urbana estabelecendo que os direitos constitucionais fundamentais, como mencionado, sejam concretizados.

Nesse contexto, antes já estava em vigor a Lei n. ${ }^{\circ}$ 6.766/1979, que expressa serem de interesse público as regularizações de parcelamentos e de assentamentos vinculados a planos ou programas habitacionais de iniciativa do poder público ou entidades autorizadas por lei (art. 53-A). Portanto, o poder público, especialmente nas esferas municipal e estadual, também deve adotar medidas eficazes para assegurar o exercício dos direitos de todos à moradia digna e acesso a um meio ambiente ecologicamente equilibrado nas cidades, contendo a ocupação desordenada do solo urbano mediante a adoção de medidas eficientes de fiscalização e 
repressão e de medidas destinadas a garantir o cumprimento da função socioambiental da propriedade.

Impõe-se, assim, a cooperação entre os entes públicos governamentais, a iniciativa privada e os demais setores da sociedade no processo de regularização fundiária urbana, em atendimento ao interesse social, constituindo-se em uma das diretrizes gerais para o fim de ordenar o pleno desenvolvimento das funções sociais da propriedade urbana (art. $2^{\circ}$, inciso III, da Lei n. ${ }^{\circ}$ 6.766/1979).

Já a Medida Provisória n. ${ }^{\circ}$ 2.220/2001 dispôs sobre a concessão de uso especial e criou o Conselho Nacional de Desenvolvimento Urbano (CNDU). Essa medida representou um avanço importante ao garantir ao ocupante (que atendesse aos requisitos legais) o direito à concessão de uso especial para fins de moradia.

A Lei n. ${ }^{\circ}$ 11.124/05 instituiu o Sistema Nacional de Habitação de Interesse Social (SNHIS), criou o Fundo Nacional de Habitação de Interesse Social (FNHIS) e instituiu o Conselho Gestor do FNHIS. O SNHIS passou a centralizar todos os programas e projetos destinados à habitação de interesse social. O FNHIS, de natureza contábil, tem o objetivo de centralizar e gerenciar recursos orçamentários para os programas estruturados no âmbito do SNHIS, destinados a implementar políticas habitacionais direcionadas à população de menor renda. E o Conselho Gestor é um órgão de caráter deliberativo, sendo composto de forma paritária por órgãos e entidades do Poder Executivo e representantes da sociedade civil. A Caixa Econômica Federal é o agente operador do FNHIS, a ela competindo, entre outros, atuar como instituição depositária dos recursos do fundo (ANDRÉ ABELHA, 2017).

A Lei n. ${ }^{\circ}$ 11.481/07 cuidou, basicamente, do acesso aos imóveis da União por beneficiários de programas habitacionais, reforçando a valorização da posse de imóveis pela população carente. Os imóveis da União, desde que desafetados, passaram a ser passíveis de alienação no âmbito de programas de regulação fundiária.

A mesma lei que instituiu o Programa Minha Casa Minha Vida (Lei n. o 11.977/09) tratou da regularização fundiária por meio do Programa Nacional de Habitação Urbana (PNHU), prevendo a legitimação de posse (ato do poder público destinado a conferir título de reconhecimento de posse de imóvel objeto de demarcação urbanística, com a identificação do ocupante e do tempo e natureza da posse) e, decorridos 5 anos do registro dessa legitimação, a sua conversão em propriedade.

Em boa hora, foi publicada a Lei n. ${ }^{\circ}$ 13.465/2017 - Lei de Regularização Fundiária, como mais um passo importante no marco regulatório da regularização fundiária urbana, ao 
instituir normas gerais e procedimentais com esse fim, impondo ao poder público a adoção de medidas "jurídicas, urbanísticas, ambientais e sociais destinadas à incorporação dos núcleos urbanos informais ao ordenamento territorial urbano e à titulação de seus ocupantes", tal como previsto em seu art. $9^{\circ}$. Para tanto, referida lei atribui, ainda, ao poder público (no âmbito da União, dos Estados, Distrito Federal e Territórios) formular e implementar no espaço urbano, políticas públicas de acordo com "os princípios de sustentabilidade econômica, social e ambiental e ordenação territorial, buscando a ocupação do solo de maneira eficiente, combinando seu uso de forma funcional” $\left(\$ 1^{\circ}\right)$. São também objeto dessa lei as ocupações e assentamentos existentes em áreas rurais.

Assim, mediante Projetos de Regularização Fundiária Urbana, pode ser conferida legitimação fundiária, hábil a reconhecer a aquisição originária de direito real de propriedade, desde que se refira a núcleos urbanos informais consolidados até 22 de dezembro de 2016 (art. $9^{\circ}, \S 2^{\circ}$, da Lei de Reurb). O procedimento, previsto no art. 35, da Lei de Reurb, nesse caso, compreende uma série de ferramentas administrativas, a serem utilizadas pelo poder público, que vão desde a identificação e classificação dos núcleos urbanos imobiliários em situação irregular, elaboração de um projeto de regularização fundiária (levantamento planialtimétrico e cadastral, com georreferenciamento, projeto urbanístico, memorial descritivo, estudo técnico ambiental e para situação de risco, proposta de soluções para questões ambientais, urbanísticas e de reassentamento dos ocupantes conforme o caso, entre outras ações), expedição da Certidão de Regularização Fundiária, e sua apresentação ao Registro de Imóveis competente para abertura de nova matrícula, individualização de matrículas ou registro de direitos reais para loteamentos urbanos (art. 44, da Lei de Reurb).

No que concerne à legislação urbanística, Silva (1997) destaca que a política nacional atribui aos municípios uma carga de responsabilização sobre os problemas sociais e habitacionais desproporcional à sua capacidade de resposta e resolução destas questões mediante políticas setoriais, daí porque a necessidade de um pacto social, como referido.

Importa, ainda, referir que todo o trâmite e a consolidação da legitimação fundiária se dá administrativamente, a culminar com aquisição originária de propriedade, sem a necessidade de ações judiciais, minimizando, para além dos problemas ambientais e urbanísticos, a judicialização dos conflitos. 


\section{Da Regularização Fundiária Urbana (Reurb) e a instituição da legitimação fundiária no Brasil}

Como mencionado, a Regularização Fundiária Urbana (Reurb) é o processo que inclui medidas jurídicas, urbanísticas, ambientais e sociais com a finalidade de incorporar os núcleos urbanos informais ao ordenamento territorial urbano e à titulação de seus ocupantes.

As medidas jurídicas correspondem especialmente à solução dos problemas dominiais, referentes às situações em que o ocupante de uma área pública ou privada não possui um título que lhe dê segurança jurídica sobre sua ocupação. É o aspecto da falta de um "documento" que dê a plena propriedade ao beneficiário direto da Reurb. As medidas urbanísticas dizem respeito às soluções para adequar os parcelamentos à cidade regularizada, como a implantação de infraestrutura essencial (calçamento, esgoto, energia, fornecimento de água), decorrentes dos loteamentos implantados sem atendimento das normas legais. Portanto, a realocação de moradias em face de estarem em locais sujeitos a desmoronamentos, enchentes, em locais contaminados, insalubres, entre outros, também entra nesse aspecto.

As medidas ambientais buscam superar o problema dos assentamentos implantados sem licenciamento ambiental e em desacordo com a legislação urbana e de proteção ao meio ambiente. As medidas sociais, por sua vez, dizem respeito às soluções dadas à população beneficiária da Reurb, especialmente nas ocupações por famílias de baixa renda, (mas não excluindo os demais segmentos sociais), de forma a propiciar o exercício digno do direito à moradia e à cidadania, proporcionando qualidade de vida.

Os objetivos da lei são claros, pois visam a identificar os núcleos urbanos informais; criar unidades compatíveis de planejamento urbano; priorizar a permanência dos ocupantes no local; prevenir a formação de novos núcleos urbanos informais; conceder direitos reais, preferencialmente em nome da mulher e franquear a participação dos interessados nas etapas da Reurb.

Convém também esclarecer que a Lei Federal no 13.465/2017, de 11 de julho de 2017, define três espécies de regularização fundiária, que atingem em sua totalidade as propriedades urbanas irregulares no Brasil, quais sejam: a Regularização Fundiária de Interesse Social (Reurb - S), aplicável aos núcleos urbanos informais ocupados, predominantemente, por população de baixa renda, assim declarados em ato do Poder Executivo municipal; a Regularização Fundiária de Interesse Específico (Reurb-E) - aplicável aos núcleos urbanos informais ocupados por população não qualificada na hipótese anterior e a Regularização Fundiária Inominada (ReurbI) - aplicável aos núcleos urbanos informais consolidados em data anterior à Lei do 
Parcelamento do Solo Urbano - Lei 6.766/1979, de 19 de dezembro 1979 (art. 69, da Lei n. ${ }^{\circ}$ $13.465 / 2017)$.

Destaca-se, também, o fato de que inúmeros são os instrumentos jurídicos que podem ser empregados no âmbito da Reurb. Em lista meramente exemplificativa, a lei enumera alguns deles, demonstrando a flexibilidade que dispõem aos legitimados e à administração pública. Dentre os quais, se podem citar: a) legitimação fundiária; b) usucapião; c) desapropriação em favor dos possuidores; d) arrecadação de bem vago; e) consórcio imobiliário; f) desapropriação por interesse social; g) direito de preempção; h) transferência do direito de construir; i) requisição; j) intervenção; k) alienação pela administração pública; 1) concessão de uso especial para fins de moradia; m) concessão de direito real de uso; n) doação; e o) compra e venda.

Não obstante dispor de tantos instrumentos, destaca-se como as mais significativas inovações da lei o fato de que, para fins de caracterização da Reurb, adotou-se um novo conceito de informalidade, chamado de "núcleo urbano informal", assim entendido como sendo aquele assentamento humano, com uso e características urbanas, clandestino, irregular ou no qual não foi possível realizar, por qualquer modo, a titulação de seus ocupantes, ainda que atendida a legislação vigente à época de sua implantação ou regularização. Bem como, a criação de um procedimento menos burocrático, inclusive em âmbito de aprovação e registro cartorial da Reurb, o qual se opera, em âmbito extrajudicial, perante os municípios, inclusive para fins de composição de conflitos pela via consensual.

E, uma das mais significativas alterações é a nova forma de aquisição do direito real de propriedade, denominado "legitimação fundiária", objeto central deste estudo. A legitimação fundiária, nos termos do art. 23, da Lei n. ${ }^{\circ}$ 13.465/17, constitui forma originária de aquisição do direito real de propriedade conferido por ato do poder público, exclusivamente no âmbito da Reurb, àquele que detiver em área pública ou possuir em área privada, como sua, unidade imobiliária com destinação urbana, integrante de núcleo urbano informal consolidado existente em 22 de dezembro de 2016.

Note-se que a lei definiu a legitimação fundiária como forma de aquisição originária da propriedade, limitando esta aquisição pretérita ao integrante de núcleo urbano informal consolidado existente em 22 de dezembro de 2016, ou seja, não vale para aquisições futuras. No entanto, não exige qualquer lapso temporal para que se possa obter a referida legitimação fundiária. 
A legitimação fundiária caracteriza a otimização da Reurb, visto que possibilita que o processo tradicional de regularização fundiária, título a título, para cada uma das unidades imobiliárias regularizadas, em razão do reconhecimento global da aquisição originária de propriedade, pelos beneficiários da Reurb, a partir de cadastro aprovado pelo poder público, constante em Certidão de Regularização Fundiária, expedida pelo Município processante, já pode ser registrado em Registro de Imóveis, por ato registral único, juntamente com o Projeto de Regularização Fundiária aprovado. Com a nova lei, e sendo aquisição originária, já se abre a matrícula com a área afetada pela regularização. (MARCO A. M. OLIVESKI, et al., 2018).

A simplificação procedimental da legitimação fundiária tem caráter excepcional e, assim, somente aplicável aos núcleos urbanos informais consolidados, ou seja, àqueles existentes na data de publicação da Medida Provisória, considerada, a partir dos requisitos especificados, a consolidação e a irreversibilidade da ocupação urbana. Importante, observar, ainda, que a legitimação fundiária, enquanto forma de aquisição originária difere da usucapião, já que a permite incidir também sobre áreas públicas.

O instituto da legitimação fundiária é, portanto, uma das maiores inovações desta lei. Em contrapartida, algumas considerações importantes devem ser feitas em relação à legitimação fundiária, tendo em vista que a aplicação deste novo instituto, sem critério de renda, tempo de posse, propriedade única e utilização, pode gerar considerável insegurança jurídica. (OLIVESKI, et al., 2018). Sua utilização indiscriminada e sem critérios igualmente pode atentar contra a probidade administrativa e a boa gestão do patrimônio público.

\section{Do processo Administrativo da Regularização Fundiária Urbana}

Inicialmente vale esclarecer que a Regularização Fundiária Urbana é composta por duas fases muito bem definidas. A primeira fase caracteriza-se pelo procedimento administrativo realizado pelo Município com a finalidade de reconhecimento da legitimação da posse ou legitimação fundiária por meio da expedição da Certidão de Regularização Fundiária (CRF) e a segunda fase é aquela referente à prenotação da Certidão de Regularização Fundiária no Registro de Imóveis competente para qualificação, análise e registro do título.

Em linhas gerais, a primeira fase do procedimento de constituição da CRF inicia com o requerimento dos legitimados previstos no art. 14, Lei n. ${ }^{\circ}$ 13.465/17 - União, Estado, DF ou Município, diretamente ou por meio de entidades da Administração Pública indireta; seus beneficiários individual ou coletivamente, cooperativas habitacionais, associações de moradores, fundações, organizações sociais, organizações da sociedade civil de interesse 
público ou outras associações civis que tenham por finalidade atividades nas áreas de desenvolvimento urbano ou regularização fundiária urbana; proprietários de imóveis ou de terrenos, loteadores ou incorporadores; Defensoria Pública, em nome dos beneficiários hipossuficientes econômicos, o que ocorre apenas na Reurb S; e Ministério Público.

Nos termos do art. 30, da Lei n. $.^{\circ} 13.465 / 17$, compete ao Município o processamento do procedimento para classificar o núcleo urbano informal dentre as modalidades de Reurb, processar, analisar e aprovar o projeto de regularização fundiária, bem como, emitir a CRF. Nos termos do art. 19, da Lei n. ${ }^{\circ}$ 13.465/17, faculta-se ao poder público utilizar-se do procedimento de demarcação urbanística para identificar núcleos urbanos informais, classificá-los e levantar dados relevantes para fins de Reurb.

Recebido o requerimento, devidamente processado e classificado pela municipalidade, deve ser concedido o prazo de 30 dias para que os titulares de direitos reais e o confrontante se manifestem. As notificações dos proprietários, confinantes e terceiros identificados deverão ser feitas pela via postal, com aviso de recebimento no endereço constante da matrícula ou da transcrição, consideradas efetuadas, quando comprovada a entrega nos endereços, podendo, ainda, se proceder a notificação por edital quando os proprietários e confinantes não forem encontrados, ou quando houver recusa no recebimento da notificação por qualquer motivo. Decorrido o prazo de 30 dias corridos da notificação, sem manifestação do notificado, interpreta-se seu silêncio como aceite, concordância.

Na hipótese de apresentação de impugnação, é iniciado procedimento extrajudicial de composição de conflito, sendo que os municípios podem criar Câmaras de Prevenção e Resolução Administrativa de Conflitos no âmbito da Administração Pública local, inclusive celebrando convênios com os Tribunais de Justiça locais, para utilização das estruturas dos CEJUSC ou das Câmaras de Mediação Credenciadas pelos tribunais estaduais, sendo certo que, se houver consenso entre as partes, o acordo deve ser reduzido a termo e constitui condição para conclusão da Reurb.

Superadas as impugnações, será iniciada a fase de elaboração do projeto de regularização fundiária, conforme o art. 35, da Lei n. ${ }^{\circ}$ 13465/17. Há também a previsão de uma fase de saneamento do projeto administrativo, indispensável para identificação de irregularidades ou falhas no expediente, observância do devido afastamento de todas as impugnações apresentadas, bem assim, da viabilidade de prosseguimento do procedimento 
administrativo sobre toda a área ou parte dela, seguida de decisão da autoridade competente, mediante ato formal ao qual se deve dar publicidade.

Finalizada esta etapa, tem-se a expedição da Certidão de Regularização Fundiária pelo Município - reconhecendo a legitimação de posse (art. 25) ou legitimação fundiária (art. 23) título hábil para apresentação e prenotação perante o Registro de Imóveis competente.

O registro da CRF e do projeto de regularização fundiária aprovado (art. 35, da Lei n. ${ }^{\circ}$ 13.465/2017) será requerido por qualquer um dos legitimados do art. 14, da Lei no 13.465/2017 diretamente ao Oficial do Cartório de Registro de Imóveis da situação do imóvel e será efetivado independentemente de determinação judicial ou do Ministério Público.

O Oficial do Registro de Imóveis possui o prazo de 15 dias contados da prenotação para emitir nota devolutiva ou praticar os atos de registro. Em caso de recusa do registro, o Oficial do Registro de Imóveis expedirá nota devolutiva fundamentada, na qual indicará os motivos da recusa e formulará exigências nos termos da lei. Discordando o interessado das exigências formalmente formuladas pelo Registrador de Imóveis, poderá requerer a suscitação de dúvida administrativa perante o Juiz Corregedor Permanente.

Dispõe, ainda, o art. 44, da Lei n. ${ }^{\circ} 13.465 / 2017$ que o registro do projeto Reurb aprovado importa em abertura de nova matrícula, quando for o caso, abertura de matrículas individualizadas para os lotes e áreas públicas resultantes do projeto de regularização aprovado ou registro dos direitos reais indicados na CRF junto às matrículas dos respectivos lotes, dispensada a apresentação de título individualizado. Referido dispositivo legal ressalta, ainda, que, quando o núcleo urbano regularizado abranger mais de uma matrícula, o oficial do registro imobiliário abrirá nova matrícula para a área objeto de regularização, conforme previsto no inciso I, do $\S 1^{\circ}$, deste artigo, destacando a área abrangida na matrícula de origem, dispensada a apuração de remanescentes.

O registro da CRF dispensa a comprovação do pagamento de tributos ou penalidades tributárias de responsabilidade dos legitimados. Devidamente registrada a CRF, serão incorporados automaticamente ao patrimônio público as vias públicas, as áreas destinadas ao uso comum do povo, os prédios públicos e os equipamentos urbanos, na forma indicada no projeto de regularização fundiária aprovado.

Denota-se, portanto, que é indispensável para o sucesso da Regularização Fundiária Urbana a realização das duas fases apresentadas, pois, do contrário, ainda será perpetuada a situação de irregularidade ocupacional do núcleo urbano informal. 


\title{
5 Extensão universitária e desenvolvimento regional: o Projeto de Extensão (Unijuí)
} “Regularização fundiária urbana (REURB): direito social à moradia digna" 2019/2020

Segundo Neil Brenner (2013), a urbanização ultrapassou as fronteiras socioespaciais, não somente entre cidade e interior, urbano e rural, centro e periferia, mas também entre escalas urbanas, regionais, nacionais e globais. Partindo da hipótese radical de Lefebvre (2001), da urbanização completa da sociedade, o pensamento crítico de Brenner tem buscado constituir um novo modelo de urbanização, orientado para a reapropriação coletiva e autogestão democrática do espaço urbano como resultado do trabalho coletivo da espécie humana.

Ainda, sobre planejamento e controle urbano, cabe destacar o caráter participativo dos planos diretores, determinado pelo Estatuto das Cidades - Lei n. ${ }^{\circ}$ 10.257/2001, que regulamenta os artigos 182 e 183 da Constituição Federal, e estabelece diretrizes gerais da política urbana, como mencionado. Neste sentido, sobre os espaços públicos, Sérgio Allebrandt (2012, p. 159) afirma que

\begin{abstract}
a legitimidade das decisões deve ter origem em espaços de discussão orientados pelos princípios da inclusão, do pluralismo, da igualdade participativa, da autonomia e do bem comum. Espaços nos quais se articulam diferentes atores que vocalizam suas pretensões com o propósito de planejar, executar e avaliar políticas públicas ou decisões de produção.
\end{abstract}

Ignacy Sachs (2012, p. 13) destaca a atenção especial que deve ser despendida para a redução das desigualdades sociais, tendo em mente que "em um planeta com recursos finitos, não é possível o crescimento infinito da produção material, indicando que idealmente poderíamos passar de uma economia de crescimento contínuo para uma economia de estado constante".

Embora não se conheçam pesquisas oficiais que quantifiquem a irregularidade fundiária do país, visto que os cadastros públicos são desatualizados e, muitas vezes, nem o próprio morador conhece a necessidade de que seu imóvel deve ser registrado no Cartório de Registro de Imóveis, a Exposição de Motivos da Lei n. ${ }^{\circ}$ 13.465/2017 observa que só o Ministério das Cidades recebeu, nos últimos quatro anos, pedidos de recursos para a regularização fundiária de mais de quatro milhões de unidades imobiliárias em todo o Brasil. Muitas dessas ocupações originam-se de contratações legítimas. Ocorre que seus ocupantes, quando muito, possuem, apenas, escrituras sem registro ou mesmo documentos particulares inaptos ao ingresso nos registros imobiliários. São localidades, bairros e, eventualmente, 
municípios inteiros em condição de informalidade, o que desordena as cidades, com vasto leque de consequências negativas para o bem-estar da população e o desenvolvimento local.

Visando a reduzir as repercussões negativas do uso, parcelamento ou ocupação do solo urbano irregular, a Lei n. ${ }^{\circ}$ 13.465/2017 adotou, para fins de Reurb, o conceito funcional dos núcleos urbanos, assim considerados como adensamentos com usos e características urbanas, ainda que situados em áreas rurais, em imóveis privados, públicos ou em copropriedade ou comunhão com ente público ou privado, destinados à moradia ou para atividade comercial dos seus ocupantes. É importante ressaltar, ainda, que a propriedade e a posse urbanas devem atender à função social, aspecto presente na Constituição Federal de 1988 e que foi regulamentado pelo Estatuto da Cidade (ARRUDA ALVIM, 2014).

A localização desses núcleos está geralmente afastada dos centros urbanos, os quais carecem de forma geral de urbanização, mobilidade, serviços públicos e infraestrutura. Quanto à questão da centralidade e compactação urbana "evidências indicam que o modo que naturalmente ocorre a descontinuidade espacial da forma urbana fragmentada tende a manter a distribuição desigual das facilidades urbanas e a promover a segregação espacial.” (OTÁVIO PERES, 2010, p 121).

Este fenômeno de expansão urbana tem ocorrido de forma desordenada na grande maioria das cidades brasileiras, cuja realidade não é diversa nos municípios de Ijuí, Santa Rosa e Três Passos, municípios situados na região noroeste do RS. Nesse contexto é que se insere o papel da extensão universitária, em especial o Projeto de Extensão denominado "Regularização Fundiária Urbana (REURB): direito social à moradia digna” que, como mencionado, envolve acadêmicos do Curso de Direito da Universidade Regional do Noroeste do Estado do RS UNIJUÍ, a ser desenvolvido com a colaboração de acadêmicos e professores dos cursos de Engenharia Civil, Arquitetura e Comunicação Social.

Referido projeto, que tem a extensão universitária como um espaço de interação acadêmica e dialógica com a sociedade, visa a promover a regularização fundiária urbana nestes municípios mediante ações concretas que vão desde o estudo e a pesquisa da legislação aplicável ao caso até a elaboração dos necessários projetos de Reurb de interesse social, com a adequação dos núcleos urbanos informais à normas sociais, urbanísticas e ambientais pertinentes, ao assessoramento técnico, culminando na outorga dos títulos de propriedade e a garantia do direito à moradia digna, em parceria, sobretudo, com o poder público municipal das cidades de abrangência do projeto. 
É sabido que a legislação brasileira estabelece normas específicas de políticas públicas que visam a tornar mais efetivo o direito social constitucional à moradia, bem como, sua regularização. É necessário acrescentar, entretanto, que a Administração Pública burocrática desempenha suas competências constitucionais de forma muito lenta, razão pela qual se justifica formar bacharéis em Direito que tenham essa visão solidária para a concretização extrajudicial do interesse público. Tais aspectos de inércia do poder público, são, de certa forma, abordados por David Harvey (2014), o qual menciona a necessidade de movimentos populares para a concretização desse direito.

Por outro lado, e paralelamente ao fenômeno jurídico, no âmbito da sociedade, muitos conflitos vêm se propagando, e acabam por reclamar a tutela jurisdicional do Estado para, por meio de ações de usucapião, que podem se arrastar por anos, cidadãos de diversos segmentos sociais buscam ver reconhecida e declarada a aquisição originária da propriedade, desde que não se trate de posse, ainda que com animus domini, de área pública. Inúmeras demandas dessa natureza acabam por desembocar nos Núcleos de Prática Jurídica dos Cursos de Direito das Universidades, bem como, nas Defensorias Públicas, em razão da vulnerabilidade social e hipossuficiência financeira dos interessados.

A delimitação do problema social, a justificar a elaboração do projeto foi delineada a partir da atuação do Escritório Modelo do Curso de Graduação em Direito da UNIJUí junto à comunidade externa, na prestação de serviços de assistência judiciária gratuita, nas cidades de Ijuí, Santa Rosa e Três Passos. Referida atuação propiciou identificar que há uma série de demandas que envolvem, em especial, uma parcela da população vulnerável social e economicamente, que adquiriu a posse de imóveis, com a expectativa de aquisição da propriedade, ou que ocupa imóveis em situação irregular, e que não tem condições de obter o título de propriedade, em razão da condição irregular ou clandestina da posse.

Nesse contexto, a abordagem do projeto parte de uma preocupação inicial com a realidade de um número considerável de moradores de núcleos urbanos informais, que se concentram tanto em loteamentos irregulares e clandestinos, quanto em conjuntos habitacionais irregulares. Tal situação faz com que vivam à margem da sociedade, especialmente em áreas de maior vulnerabilidade social, em condições precárias ou até inexistentes de infraestrutura adequada, e, inclusive, de invasão a áreas de preservação permanente, criando um risco ambiental que precisa ser contido. 
Em contrapartida, proliferam-se os conflitos sociais, na tentativa, não raras as vezes, inexitosa, de regularização dos imóveis possuídos, adquiridos ou ocupados. Deste modo, se torna imprescindível a implementação de ações, em parceria com o poder público municipal, e com outros agentes públicos e sociais, que tenham por base a promoção do direito social à moradia digna, crucial para um desenvolvimento regional sustentável. Esta intervenção pressupõe que os indivíduos a serem beneficiados tenham acesso à moradia regular e as demais benesses dela decorrentes, numa perspectiva emancipatória, superando a marginalidade e a clandestinidade da moradia.

Partindo-se da ideia de que "a questão da regularização fundiária urbana pode tornarse um consenso" (ELENISE SCHONARDIE, 2012, p. 266), já que a preocupação com a regular ocupação do espaço público urbano e a complexidade dos problemas sociais decorrentes da moradia irregular interessam a vários segmentos da sociedade civil, o papel da extensão universitária nesse contexto é relevante, não só para fins de legitimar um pacto social, mas para propiciar, a partir dessa compreensão, o desenvolvimento regional.

Nesse sentido, o projeto se caracteriza como uma prática acadêmica e social que visa a reafirmar o compromisso da Unijuí com o desenvolvimento regional sustentável, mediante ações e medidas eficazes para assegurar o exercício dos direitos de todos à moradia digna e acesso a um meio ambiente ecologicamente equilibrado nas cidades, contendo a ocupação desordenada do solo, mediante o fomento do poder público a promover a regularização fundiária urbana, com medidas destinadas a garantir o cumprimento da função socioambiental da propriedade. Desse modo, interliga a universidade às demandas da sociedade, privilegiando a condição humana, a emancipação e o protagonismo dos sujeitos, a partir da formação de profissionais e cidadãos preparados para o enfrentamento das problemáticas sociais, articulados com vários segmentos da sociedade, a contribuir para a promoção da inclusão social.

Tendo como público-alvo moradores de loteamentos clandestinos ou irregulares, moradores de conjuntos habitacionais urbanos em situação irregular, organizações e/ou movimentos populares, associações de moradores de bairros, e autoridades locais do Poder Executivo Municipal, da Defensoria Pública, do Ministério Público e do Cartório de Registro de Imóveis, o Projeto de Extensão Reurb está sendo desenvolvido a partir de uma metodologia de intervenção apta a definir o conjunto de meios dispostos convenientemente para investigar o tema ou a problemática escolhida, concretizando-se em etapas ou momentos a serem seguidos em um processo de investigação ou intervenção científica. 
A fim de atingir os objetivos propostos, referido projeto será desenvolvido ao longo dos anos de 2019 e 2020, mediante as seguintes ações: a) realização sistemática e continuada de oficinas de estudo e pesquisa com a equipe de trabalho, acerca da legislação pertinente à regularização fundiária urbana; b) levantamento de dados junto à municipalidade e, também, por meio de pesquisa de campo, a fim de identificar, quantitativa e qualitativamente, a população de moradores dos núcleos urbanos informais; c) realização de reuniões com as associações de moradores dos bairros, a fim de socializar informações e orientar os interessados para o encaminhamento dos processos administrativos de regularização fundiária urbana; d) participação em eventos, programas de rádio, e realização, em parceria com agentes públicos e sociais, de palestras e oficinas nos espaços comunitários que compreendam o público alvo do projeto; e) orientação e acompanhamento profissional (jurídico, arquitetônico urbanístico, ambiental) dos moradores para o trâmite administrativo junto ao poder público municipal para a regularização das propriedades cuja posse é irregular ou clandestina; f) orientação e acompanhamento profissional dos moradores para expedição da Certidão de Regularização Fundiária (CRF); e g) assessoria para o processo de registro das propriedades, com abertura de matrículas individualizadas, junto ao Cartório de Registro Imobiliário.

A estimativa do número de pessoas a serem beneficiadas pelo projeto não é possível precisar antes de sua implementação, tendo em vista que uma das ações compreenderá uma pesquisa de campo a fim de que possam ser quantificados os dados. No entanto, ao se compreender seu caráter extensionista, pode-se afirmar que beneficiará, direta ou indiretamente, toda a população das três cidades envolvidas no projeto, tendo em vista que seus resultados poderão contribuir para uma melhoria na qualidade de vida, a conter um aumento no processo de expansão e de ocupação irregular do solo urbano.

E, por outro lado, acredita-se que projetos de extensão universitária como os que ora se apresenta têm uma importante contribuição para a formação acadêmica e profissional dos graduando envolvidos, já que seu envolvimento no projeto permitirá que conheçam distintas realidades e participem (de forma propositiva, inclusive) de ações que objetivam a emancipação do público atendido, assegurando o necessário compromisso daqueles com a dimensão da cidadania e da dignidade humana, inerentes à formação acadêmica. Ainda, o contato dos professores com as distintas realidades vivenciadas pelos grupos atendidos é fundamental para a qualificação da atuação docente, uma vez que as vivências e ações desenvolvidas redimensionarão os conhecimentos teóricos trabalhados em aula, refletindo em todo o corpo 
discente dos cursos envolvidos. E, por fim, a socialização das experiências e dos dados coletados poderão fomentar nos graduandos o interesse pela pesquisa de questões sociais e acadêmicas de modo geral.

\section{Considerações Finais}

É no espaço urbano que se colocarão os maiores desafios para a convivência de nossa espécie e do nosso futuro. A sociedade contemporânea está cada vez mais urbana e globalizada e novos desafios ao conhecimento estão postos para pesquisas e desenvolvimento intelectual.

Nesse contexto, a ocupação desordenada do espaço urbano é uma questão a ser enfrentada e que, acredita-se, ser de interesse da sociedade como um todo, e não apenas do poder estatal. Dessa concepção, resulta também o interesse coletivo para a regularização de parcelamentos e assentamentos vinculados a planos ou programas habitacionais de iniciativa do poder público. Nesse viés, o poder público, especialmente nas esferas municipal e estadual, em parceria com a sociedade civil, deve adotar medidas eficazes para assegurar o exercício dos direitos de todos à moradia digna e acesso a um meio ambiente ecologicamente equilibrado nas cidades, mediante a adoção de medidas eficientes de fiscalização e repressão e de medidas destinadas a garantir o cumprimento da função socioambiental da propriedade, a promover o desenvolvimento das funções sociais da propriedade urbana.

Como demonstrado, a construção do espaço público em inúmeros núcleos urbanos informais existentes nos municípios abrangidos pelo Projeto de Extensão REURB, da UNIJUI, foi marcada por algum tipo de ocupação clandestina ou irregular, consolidando-se, inclusive em áreas de risco aos moradores.

O projeto de extensão universitária apresentado no presente texto possibilita uma aproximação conceitual sobre o tema do parcelamento do solo urbano, com o intuito de analisar os fatos do ponto de vista teórico, para posteriormente confrontar a visão teórica com os dados da realidade empírica.

Em contrapartida, contribui para a implementação de ações, em parceria com o poder público municipal, e com outros agentes públicos e sociais, que tenham por base a promoção do direito social à moradia digna, crucial para um desenvolvimento regional sustentável. Esta intervenção pressupõe que os indivíduos a serem beneficiados tenham o acesso à moradia regular e às demais benesses dela decorrentes, numa perspectiva emancipatória, superando a marginalidade e a clandestinidade da moradia. 
Sendo assim, as ações propostas pelo Projeto de REURB, em parceria com o poder público dos respectivos Municípios, contemplarão não somente os moradores que se encontram nesta situação, mas a população como um todo. Sua implementação promoverá a adequação dos núcleos urbanos informais às normas urbanísticas e ambientais, de saneamento básico e de infraestrutura adequada, notadamente pelo projeto e execução de obras que atendam à construção ou recuperação de redes pluviais, de esgoto, de fornecimento de água e energia elétrica, de pavimentação, de instituição de áreas verdes, de espaços e serviços públicos (praças, creches, postos de saúde). Ainda, na medida do possível, contribuirá para um meio ambiente sadio e ecologicamente equilibrado, mediante a identificação e recuperação das áreas de preservação permanente. E, talvez, um dos aspectos mais importantes: dará visibilidade a um problema social que não pode mais ser negligenciado tanto pelo poder público, quanto pela sociedade civil: as condições em que vive uma considerável parcela da população urbana, que constrói seus lares "longe dos olhos" dos moradores do centro das cidades, ou dos bairros situados em áreas mais nobres, e que são privados de uma moradia digna!

Nesse sentido, programas de extensão universitária como o que ora se apresenta, além de contribuírem para uma significativa melhoria na qualidade da vida da população local e regional, possibilitam uma qualificação acadêmica e profissional, na medida em que viabilizam a interação entre o meio acadêmico e a comunidade, e capacitam futuros profissionais para o enfrentamento das questões sociais de maior complexidade, com vistas a uma formação humanista.

\section{Referências Bibliográficas}

ABELHA, André. Lei 13.465/17 (Parte VI): desmistificando a Reurb. Disponível em: <https://www.migalhas.com.br/dePeso/16,MI264717,61044lei+1346517+Parte+VI+desmistif icando+a+Reurb>. Acesso em: 30 mar. 2019.

ALLEBRANDT, Sérgio Luís. Estado, administração pública e gestão social. In: SIEDENBERG, Dieter Rugard (Org.). Desenvolvimento sob Múltiplos Olhares. Coleção Gestão e Desenvolvimento. Ijuí: Unijuí, 2012.

ARRUDA ALVIM, José Manoel de. A função social da propriedade e os diversos tipos de propriedade, e a função social da posse. In: ARRUDA ALVIM, José Manoel de; CAMBLER, Everaldo Augusto (Coord.). Estatuto da cidade. São Paulo: Revista dos Tribunais, 2014.

BRASIL. Presidência da República. Casa Civil. Subchefia para Assuntos Jurídicos. Constituição da República Federativa do Brasil. Brasília, 1988. Disponível em: 
<www.planalto.gov.br/ccivil_03/constituicao/ConstituicaoCompilado.htm>. Acesso em: 30 março 2019.

Presidência da República. Casa Civil. Subchefia para Assuntos Jurídicos. Lei Complementar $\quad \mathbf{n}^{\mathbf{0}} \quad \mathbf{6 . 7 6 6 / 1 9 7 9}$. Brasília, 1979. Disponível em: <http://www.planalto.gov.br/ccivil_03/leis/L6766.htm>. Acesso em: 26 ago. 2018.

Presidência da República. Casa Civil. Subchefia para Assuntos Jurídicos. Medida Provisória $\mathbf{n}^{\mathbf{0}}$ 2.020, de 04 de setembro de 2001. Brasília, 2001. Disponível em: < http://www.planalto.gov.br/ccivil_03/MPV/2220.htm>. Acesso em 19 dez. 2017.

. Presidência da República. Casa Civil. Subchefia para Assuntos Jurídicos. Lei Federal $\mathbf{n}^{\mathbf{0}}$ 10.257, 10 de Julho de 2001. Regulamenta os arts. 182 e 183 da Constituição Federal, estabelece diretrizes gerais da política urbana e dá outras providências. Disponível em: <http://www.planalto.gov.br/ccivil_03/leis/LEIS_2001/L10257.htm>. Acesso em: 10 out. 2018.

Presidência da República. Casa Civil. Subchefia para Assuntos Jurídicos. Lei Federal no 11.124, 16 de junho de 2005. Dispõe sobre o Sistema Nacional de Habitação de Interesse Social - SNHIS, cria o Fundo Nacional de Habitação de Interesse Social - FNHIS e institui o Conselho Gestor do FNHIS. Disponível em: $<$ https://www2.camara.leg.br/legin/fed/lei/2005/lei-11124-16-junho-2005-537348-normapl.html>. Acesso em 10 out. 2018.

Presidência da República. Casa Civil. Subchefia para Assuntos Jurídicos. Lei Federal no 11.481, 30 de maio de 2007. Dá nova redação a dispositivos das Leis $n^{\text {os }} 9.636$, de 15 de maio de 1998, 8.666, de 21 de junho de 1993, 11.124, de 16 de junho de 2005, 10.406, de 10 de janeiro de 2002 - Código Civil, 9.514, de 20 de novembro de 1997, e 6.015, de 31 de dezembro de 1973, e dos Decretos-Leis $\mathrm{n}^{\text {os }}$ 9.760, de 5 de setembro de 1946, 271, de 28 de fevereiro de 1967, 1.876, de 15 de julho de 1981, e 2.398, de 21 de dezembro de 1987; prevê medidas voltadas à regularização fundiária de interesse social em imóveis da União; e dá outras providências. Disponível em: <http://www.planalto.gov.br/CCIVIL_03/_Ato20072010/2007/Lei/L11481.htm>. Acesso em 10 out. 2018.

Presidência da República. Casa Civil. Subchefia para Assuntos Jurídicos. Lei Federal $\mathbf{n}^{\circ}$ 11.977, 07 de julho de 2009. Dispõe sobre o Programa Minha Casa, Minha Vida - PMCMV e a regularização fundiária de assentamentos localizados em áreas urbanas; altera o DecretoLei $\mathrm{n}-3.365$, de 21 de junho de 1941, as Leis $\mathrm{n}$ os 4.380, de 21 de agosto de 1964, 6.015, de 31 de dezembro de 1973, 8.036, de 11 de maio de 1990, e 10.257, de 10 de julho de 2001, e a Medida Provisória no 2.197-43, de 24 de agosto de 2001; e dá outras providências. Disponível em: <http://www.planalto.gov.br/ccivil_03/_Ato2007-2010/2009/Lei/L11977.htm>. Acesso em 10 out. 2018.

Presidência da República. Casa Civil. Subchefia para Assuntos Jurídicos. Lei Federal $\mathbf{n}^{\circ}$ 13.465, 27 de julho de 2017. Dispõe sobre a regularização fundiária rural e urbana, sobre a liquidação de créditos concedidos aos assentados da reforma agrária e sobre a regularização fundiária no âmbito da Amazônia Legal; institui mecanismos para aprimorar a eficiência dos procedimentos de alienação de imóveis da União; altera as Leis nos 8.629, de 25 de fevereiro de 1993, 13.001, de 20 de junho de 2014, 11.952, de 25 de junho de 2009, 13.340, de 28 de setembro de 2016, 8.666, de 21 de junho de 1993, 6.015, de 31 de dezembro de 1973, 12.512, 
de 14 de outubro de 2011,10.406, de 10 de janeiro de 2002 (Código Civil), 13.105, de 16 de março de 2015 (Código de Processo Civil), 11.977, de 7 de julho de 2009, 9.514, de 20 de novembro de 1997, 11.124, de 16 de junho de 2005, 6.766, de 19 de dezembro de 1979, 10.257, de 10 de julho de 2001, 12.651, de 25 de maio de 2012, 13.240, de 30 de dezembro de 2015, 9.636, de 15 de maio de 1998, 8.036, de 11 de maio de 1990, 13.139, de 26 de junho de 2015, 11.483, de 31 de maio de 2007, e a 12.712, de 30 de agosto de 2012, a Medida Provisória no 2.220, de 4 de setembro de 2001, e os Decretos-Leis nos 2.398, de 21 de dezembro de 1987, 1.876, de 15 de julho de 1981, 9.760, de 5 de setembro de 1946, e 3.365, de 21 de junho de 1941; revoga dispositivos da Lei Complementar no76, de 6 de julho de 1993, e da Lei no 13.347, de 10 de outubro de 2016; e dá outras providências. Disponível em: <http://www.planalto.gov.br/ccivil_03/_Ato2015-2018/2017/Lei/L13465.htm>. Acesso em: 10 outubro 2018.

BRENNER, Neil. Theses on urbanization. Public Culture. Durham, v. 25, n. 1, 2013.

DECLARAÇÃO UNIVERSAL DOS DIREITOS HUMANOS. 10 dezembro 1948. Disponível em: <https://nacoesunidas.org/wp-content/uploads/2018/10/DUDH.pdf>. Acesso em: 10 outubro 2018.

HARVEY, David. Cidades rebeldes: do direito à cidade à revolução urbana. trad. Jeferson Camargo. São Paulo: Martins Fontes, 2014.

LEFEBVRE, Henri. O direito à cidade. trad. Rubens Eduardo Frias. São Paulo: Centauro, 2001.

OLIVESKI, Marco Aurélio Marques; ALLEBRANDT, Sérgio Luís; MUELLER, Airton Ademar \& OLIVESKI, Patricia Marques. As políticas públicas de parcelamento e uso do solo urbano: uma análise da nova lei federal de regularização fundiária (13.465/17) e o direito à moradia em áreas urbanas. In: (Re)Pensando Direito. V.8. n. 15. Santo Ângelo, 2018. Disponível em http://local.cnecsan.edu.br/revista/index.php/direito. Acesso em Outubro, 2018.

PERES, Otávio Martins. Crescimento Urbano e Hidrografia: dinâmicas morfológicas e articulação à paisagem natural. Pelotas, 2010. Dissertação (Mestrado em Arquitetura e Urbanismo) - Faculdade de Arquitetura e Urbanismo da Universidade Federal de Pelotas.

SACHS, Ignacy. De volta à mão visível: os desafios da Segunda Cúpula da Terra no Rio de Janeiro. Estudos Avançados, V. 26, n. 74, 2012.

SAULE JR., Nelson.; UZZO, Karina. A trajetória da reforma urbana no Brasil. Ciudades para tod@s, Experiencias, Marco Legal. Recife, 2015. Disponível em: $<$ http://www.redbcm.com.br/arquivos/Bibliografia/a\%20trajectoria\%20n\%20saule\%20k\%20u zzo.pdf>. Acesso em: 04 abr. 2019.

SILVA, Helena Maria Menna Barreto. Terra e moradia. São Paulo, 1997. Tese (Doutorado em Arquitetura e Urbanismo) - Faculdade de Arquitetura e Urbanismo da Universidade de São Paulo. 
SHONARDIE, Elenise Felzke. Direito à cidade e favelização. In: BEDIN, Gilmar Antonio (org.). Cidadania, direitos humanos e equidade. Coleção direito, política e cidadania. Ijuí: Ed. Unijuí, 2012.

TAVOLARI, Bianca; BERTH, Joice. Direito à cidade. In: Cidades Educadoras. Disponível em: <https://cidadeseducadoras.org.br/glossario/direito-a-cidade/>. Acesso em: 08 out. 2018. 